\title{
COMPARING CLIMATE COMMITMENTS: A MODEL-BASED ANALYSIS OF THE COPENHAGEN ACCORD
}

\author{
WARWICK J. MCKIBBIN \\ Research School of Economics \\ ANU College of Business and Economics \\ Arndt Building (25) \\ The Australian National University \\ Canberra ACT 0200, Australia \\ Warwick.McKibbin@anu.edu.au \\ and \\ The Brookings Institution \\ 1775, Massachusetts Ave \\ NW, Washington DC 20036 \\ wmckibbin@brookings.edu
}

ADELE C. MORRIS*

The Brookings Institution

1775, Massachusetts Ave

NW, Washington DC 20036

amorris@brookings.edu

\section{PETER J. WILCOXEN}

The Maxwell School, Syracuse University, Syracuse

NY 13244

wilcoxen@syr.edu

and

The Brookings Institution

Brookings 1775, Massachusetts Ave

NW, Washington DC 20036

\begin{abstract}
The political accord struck by leaders at the United Nations negotiations in Copenhagen in December 2009 allows participants to express their greenhouse gas commitments in a variety of ways. This paper compares the environmental and economic performance of these disparate commitments using the G-Cubed model of the global economy. We focus on fossil-fuel-related $\mathrm{CO}_{2}$ and assume targets are achieved domestically. We show how different formulations make the same targets appear different in stringency and explore the Accord's spillover effects across countries. We find that commitments by Japan and Europe imply high carbon prices and relatively high GDP losses. The United States and China both have moderate carbon prices and moderate GDP effects. Australia and Eastern Europe/Former Soviet Union have relatively large
\end{abstract}

\footnotetext{
*Corresponding author.
} 
GDP effects despite small or zero carbon prices because their terms of trade decline. OPEC suffers a large drop in GDP from a sharp decline in world oil demand.

Keywords: Climate treaty; Copenhagen Accord; climate commitments; international climate cooperation; climate change economics; comparability of efforts; climate agreements.

\section{Introduction}

World leaders met in Copenhagen in December 2009 for the 15th Conference of the Parties (COP) to the United Nations Framework Convention on Climate Change (UNFCCC). The resulting agreement, called the Copenhagen Accord (the Accord), is not legally binding. However, heads of state struck the deal personally so it carries significant political weight. Negotiations are currently underway towards a more enforceable agreement, but prospects for its conclusion before the end of the Kyoto Protocol's commitment period in 2012 are uncertain. Thus, the Copenhagen Accord reflects the broad willingness of major economies to commit, at least politically, to measurable emissions limitations through 2020.

Emissions commitments by Annex I countries appear in Appendix I of the Accord, formulated as economy-wide reductions in greenhouse gas emissions relative to a base year of each country's choosing. ${ }^{1}$ Developing countries' commitments appear in Appendix II of the Accord. ${ }^{2}$ Their commitments are more varied and include, for example, emissions reduction targets relative to business as usual projections, reductions in emissions per unit of gross domestic product (GDP), expansions in forest cover, and investments in energy efficiency and biofuels.

Table 1 reports the commitments of some of the largest emitters as they were reported to the UNFCCC. As might be expected given that the Accord is not a legally binding document, these commitments are different in several ways from the commitments by Parties to the Kyoto Protocol. For example, the Accord targets refer only to a single year's emissions, 2020, whereas the Kyoto Protocol capped total emissions over a five year period. The Accord makes no mention of the paths of emissions from 2013, the first year after the Kyoto Protocol compliance period, through 2019. The Accord is also silent about the degree to which targets would be met domestically or through emissions trading or international offsets.

As Table 1 reports, some Accord participants offered ranges of emissions targets, with more stringent levels being contingent on other countries' actions or the enactment of domestic legislation. For example, the E.U. offers an unconditional 20 percent reduction and a 30 percent reduction contingent on "comparable emissions reductions" by other developed countries and "adequate contributions" by developing countries. While the Kyoto targets are predominantly percentage reductions in emissions relative to 1990 levels, averaged over 2008 to 2012, the base years of emissions reduction targets in the Copenhagen Accord differ across participants. The U.S. and Canada both

\footnotetext{
${ }^{1}$ Appendix I of the Copenhagen Accord is available here: http://unfecc.int/home/items/5264.php.

${ }^{2}$ Appendix II of the Copenhagen Accord is available here: http://unfccc.int/home/items/5265.php.
} 
Table 1. Commitments under the Copenhagen Accord.

\begin{tabular}{|c|c|c|}
\hline Country & Greenhouse gas emissions targets for 2020 & Base year \\
\hline USA & $\begin{array}{l}\text { [Reduction of emissions] in the range of } 17 \% \text {, in conformity with } \\
\text { anticipated U.S. energy and climate legislation, recognizing that } \\
\text { the final target will be reported to the Secretariat in light of } \\
\text { enacted legislation. }\end{array}$ & 2005 \\
\hline Japan & $\begin{array}{l}25 \% \text { reduction, which is premised on the establishment of a fair } \\
\text { and effective international framework in which all major } \\
\text { economies participate and on agreement by those economies on } \\
\text { ambitious targets. }\end{array}$ & 1990 \\
\hline Australia & $\begin{array}{l}5 \% \text { unconditionally; up to } 15 \% \text { or } 25 \% \text { with international action; } \\
\text { Australia will reduce its greenhouse gas emissions by } 25 \% \text { on } \\
2000 \text { levels by } 2020 \text { if the world agrees to an ambitious global } \\
\text { deal capable of stabilizing levels of greenhouse gases in the } \\
\text { atmosphere at } 450 \mathrm{ppm} \mathrm{CO}_{2} \text {-eq or lower. Australia will } \\
\text { unconditionally reduce emissions by } 5 \% \text { below } 2000 \text { levels by } \\
2020 \text {, and by up to } 15 \% \text { by } 2020 \text { if there is a global agreement } \\
\text { which falls short of securing atmospheric stabilization at } 450 \mathrm{ppm} \\
\mathrm{CO}_{2} \text {-eq and under which major developing economies commit } \\
\text { to substantially restrain emissions and advanced economies take } \\
\text { on commitments comparable to Australia's. }\end{array}$ & 2000 \\
\hline European Union & $\begin{array}{l}20 \% / 30 \% \text {; as part of a global and comprehensive agreement for the } \\
\text { period beyond } 2012 \text {, the E.U. reiterates its conditional offer to } \\
\text { move to a } 30 \% \text { reduction by } 2020 \text { compared to } 1990 \text { levels, } \\
\text { provided that other developed countries commit themselves to } \\
\text { comparable emission reductions and that developing countries } \\
\text { contribute adequately according to their responsibilities and } \\
\text { respective capabilities. }\end{array}$ & 1990 \\
\hline Canada & $\begin{array}{l}17 \% \text {, to be aligned with the final economy-wide emissions target of } \\
\text { the U.S. in enacted legislation. }\end{array}$ & 2005 \\
\hline Russia & $\begin{array}{l}\text { 15-25\%; the range of the GHG emission reductions will depend on } \\
\text { the following conditions: } \\
\text { - Appropriate accounting of the potential of Russia's forestry in } \\
\text { frame of contribution in meeting the obligations of the } \\
\text { anthropogenic emissions reduction; } \\
\text { - Undertaking by all major emitters the legally binding } \\
\text { obligations to reduce anthropogenic GHG emissions. }\end{array}$ & 1990 \\
\hline China & $\begin{array}{l}\text { Lower } \mathrm{CO}_{2} \text { emissions per unit of GDP by } 40-45 \% \text {; } \\
\text { Increase the share of non-fossil fuels in primary energy } \\
\text { consumption to around } 15 \% \text {; } \\
\text { Increase forest coverage by } 40 \text { million hectares and forest stock } \\
\text { volume by } 1.3 \text { billion cubic meters }\end{array}$ & 2005 \\
\hline India & $\begin{array}{l}\text { Reduce the emissions intensity of its GDP by } 20-25 \% \text { by } 2020 \text { in } \\
\text { comparison to the } 2005 \text { level. }\end{array}$ & 2005 \\
\hline
\end{tabular}


promised reductions of $17 \%$ relative to 2005 levels, while the E.U., Russia, and Japan chose a base year of 1990. Australia opted for 2000.

Notably, unlike under the Kyoto Protocol, some major developing countries made economy-wide emissions commitments in the Accord. In particular, China and India committed to reducing by 40 and 20 percent reductions respectively their emissions per unit of GDP. This approach is consistent with many developing countries' longstanding opposition to hard emissions limits on the grounds that limits on emissions levels could impose inadvertently stringent constraints given these countries' potentially large but uncertain economic growth. Also consistent with longstanding positions, both countries cite in their Copenhagen commitments the UNFCCC provision that stipulates that developing country actions depend on developed country actions, including the provision of financial resources and technology transfer. ${ }^{3}$

The presumption that binding commitments can take only the form of a percentage reduction relative to specific historical levels hampered efforts to reach agreement, not just because it alienates rapidly industrializing countries such as China and India. All parties face uncertainty in their commitments because many factors that affect the burden of achieving the target evolve between the year of negotiation and the commitment period. The recent financial crisis and global economic downturn are clear reminders of the volatility in the underlying economic environment in which parties make these emissions commitments. Additional uncertainties include unanticipated economic growth, technology breakthroughs, prices for renewables and natural gas (a loweremitting alternative to coal), and political upheavals. The results of this paper also indicate that another source of uncertainty is the effects of other countries' mitigation actions.

Trends in national emissions and economic growth have varied widely since 1990. Also, historical patterns of energy use and marginal costs of greenhouse gas (GHG) abatement also vary widely across countries. This means that targets that look similar can require very different levels of effort in different countries, and commitments that produce similar economic outcomes can look inequitable. The tension between equivalent appearances and equivalent effort has been a chronic challenge in climate negotiations. Indeed, the failure of the G-8 to set a base year for its agreed 80 percent reduction of emissions by 2050 illustrates the contention in formulating even collective targets.

The notion that the efforts underlying different countries' climate commitments should be comparable is enshrined in the UNFCCC's 2007 Bali Plan of Action, which called for the next agreement to ensure the "comparability of efforts" across developed countries while "taking into account differences in their national circumstances." The term "comparable" has two quite distinct meanings: "similar" and "expressed in a way that can be compared." This analysis shows that under simplifying assumptions the commitments can be compared, but that different measures of outcomes lead to different conclusions about the relative "efforts" of the participants.

\footnotetext{
${ }^{3}$ UNFCCC, Article 4, Paragraph 7. The financing may or may not materialize. For example, at the 2010 UNFCCC meeting in Cancun leaders promised new funding of about $\$ 30$ billion through 2012. However, the agreement targets the funding to the least developed countries and splits it between adaptation and mitigation.
} 
The Accord's flexibility promoted consensus at Copenhagen by allowing countries to express their commitments in ways that enhance their apparent stringency, accommodate economic growth, and preserve the option for less ambitious efforts if they are not reciprocated. However, the disparate base years and commitment formulations, along with widely varying recent emissions trends and projections across different economies, make it difficult to compare the likely emissions reductions and economic efforts required to achieve these commitments. Using the G-Cubed model of the global economy, this paper estimates and compares the economic and environmental performance of major emitters' Accord commitments. We emphasize that this work is not a policy analysis or a prediction about how countries will actually achieve their commitments. Rather, it offers a way of standardizing and comparing heterogeneous proposals on the basis of their environmental and economic outcomes.

Several studies analyze the commitments within the Copenhagen Accord, nearly all with an emphasis on the potential environmental performance of the agreement. Like this study, Jotzo (2010) expresses the targets in common terms and compares them with different metrics. He finds the targets result in similar reductions in emissions intensity across countries relative to base year emissions. Emissions reductions relative to business-as-usual trajectories, however, differ significantly across countries. The study finds that China agreed to intensity reductions similar to those implicit in the targets of the U.S., E.U., Japan, Australia and Canada.

A United Nations Environment Program report summarizes thirteen other studies of the emissions implications of the Copenhagen Accord with an emphasis on whether the pledges are ambitious enough to achieve the agreed limit to global temperature increase of $2^{\circ} \mathrm{C} .{ }^{4}$ Nearly all studies of economic impacts of the emission pledges focus on a single country or region in partial equilibrium.

This study also compares the Copenhagen Accord commitments but the tools we apply and outcomes we explore differ significantly from Jotzo (2010) and others. Here, rather than extrapolating key macroeconomic variables and estimating target emissions reductions relative to those projections, we apply an intertemporal general equilibrium model of the global economy and simulate the effects of policies that achieve the specified commitments. To do this, we must construct a stylized interpretation of the agreement that applies individual countries' commitments to the regions in our model, and we must make strong simplifying assumptions about the implementation policies. In return, we can explore not just the emissions implications of the targets but also the potential economic consequences of achieving them. With a general equilibrium approach, we avoid ad hoc assumptions about economic and emissions growth and reveal ways in which efforts to achieve targets in one country can affect economies elsewhere.

A computable general equilibrium (CGE) modeling study, Dellink et al. (2010), assessed the costs and effectiveness of the Copenhagen pledges. The authors used the OECD ENV-Linkages model to find, as we do, that GDP and income impacts vary

${ }^{4} \mathrm{UNEP}(2010)$, Chapter 3. 
across countries. In their study, Annex I countries on average experience a GDP loss of approximately $0.3 \%$ from baseline levels, and a reduction in household real income of $0.5 \%$. Our study differs in its assumptions in several ways that lead to higher estimated carbon prices and higher impacts on GDP in some countries. Most importantly, our policy scenario assumes no emissions trading or offsets. We discuss this assumption in more detail below.

This is meant less to be a definitive study of the Copenhagen Accord than an elucidation of the methodological potential of general equilibrium modeling for international climate agreements with disparate commitment formulations. We also strive to broadly characterize and rank the implicit levels of economic effort required to meet the targets in a way that is independent of most implementation details. Because we analyze both the economic and environmental outcomes, we highlight the tension negotiators' face between targets that appear comparable in emissions terms and targets that imply economically similar efforts.

We estimate and compare the overall costs, price signals, and emissions outcomes of the agreement. A number of insights emerge. Climate policy debates often surround concerns about the effect of commitments on participants' own economies and the potential competitive disadvantages or emissions leakage that may result if other countries do not adopt similar measures. We find that emissions leakage in general is small, but economic spillovers can be large. Especially for fossil fuel exporters, very significant domestic consequences can arise from the adoption of the multilateral agreement elsewhere, and indeed these consequences can exceed the costs of domestic abatement efforts.

Section 2 provides a summary of the modeling approach. It describes the no-policy baseline projections for the modeled regions and the design of the Copenhagen Accord policy scenario. Section 3 explores the emissions reductions in the Accord relative to common base years and projections of business as usual emissions. We show how the choice of base year affects how stringent different targets look while implying the same actual emissions level. Section 4 explores the emissions and economic results of the Copenhagen Accord under several simplifying assumptions. Section 5 concludes.

\section{Modeling Approach}

The G-Cubed model is an intertemporal computable general equilibrium (CGE) model of the world economy. ${ }^{5}$ A brief technical discussion of G-Cubed appears in McKibbin et al. (2009) and a more detailed description of the theory behind the model can be found in McKibbin and Wilcoxen (1999).

This study uses a version of the model that includes the eleven geographical regions listed in Table 2. The U.S., Japan, Australia, China, India, and Brazil are each

\footnotetext{
${ }^{5}$ The type of intertemporal CGE model represented by G-Cubed, which has macroeconomic dynamics and various nominal rigidities, is closely related to the dynamic stochastic general equilibrium models appearing in the macroeconomic and central banking literatures.
} 
Table 2. Regions in the G-Cubed model (country aggregation D).

\begin{tabular}{cc}
\hline Region name & Region description \\
\hline USA & United States \\
Japan & Japan \\
Australia & Australia \\
Europe & Western Europe \\
ROECD & China \\
China & India \\
India & Rest of the OECD, i.e. Canada and New Zealand \\
EEFSU & Brazil \\
Brazil & Other Developing Countries \\
LDC & Oil Exporting Developing Countries \\
OPEC &
\end{tabular}

represented by a single modeled region. The model aggregates the rest of the world into five composite regions: Western Europe, the rest of the OECD (not including Mexico and Korea) (ROECD); Eastern Europe and the former Soviet Union (EEFSU); OPEC oil exporting economies; and all other developing countries (LDC). Appendix I reports the details of these regional groupings.

\subsection{The baseline scenario}

One of the most important factors in modeling emissions commitments is the model's assumptions (or in the case of G-Cubed, its endogenous projections) about future emissions and economic activity in the absence of climate policy. This is called the baseline scenario, and it is a major factor in explaining why different economic models produce different estimates for the cost of a particular emissions target: the lower emissions are in the reference scenario, the less abatement is needed to hit a particular cap. A detailed discussion of the baseline and how it is generated in G-Cubed can be found in McKibbin, Pearce and Stegman (2009).

In this study, we construct a baseline scenario for the entire world that reflects our best estimate of the likely evolution of each region's economy without concerted climate policy measures. To generate this scenario, we begin by calibrating the model to reproduce approximately the relationship between economic growth and emissions growth in the U.S. and other regions over the past decade. Appendix II reports more details about the projections in the baseline scenario and how they compare to analogous projections in the Energy Information Administration's International Energy Outlook.

In the baseline, no country adopts an economy-wide price on carbon through 2050, including the E.U. Although some countries in the model have commitments under the Kyoto Protocol, most do not currently have an economy-wide price on carbon or anything close to it, with the E.U. a notable exception. Kyoto Protocol participants may or may not actually achieve their targets, and those that do (such as Russia) may do so without strong policy measures. 


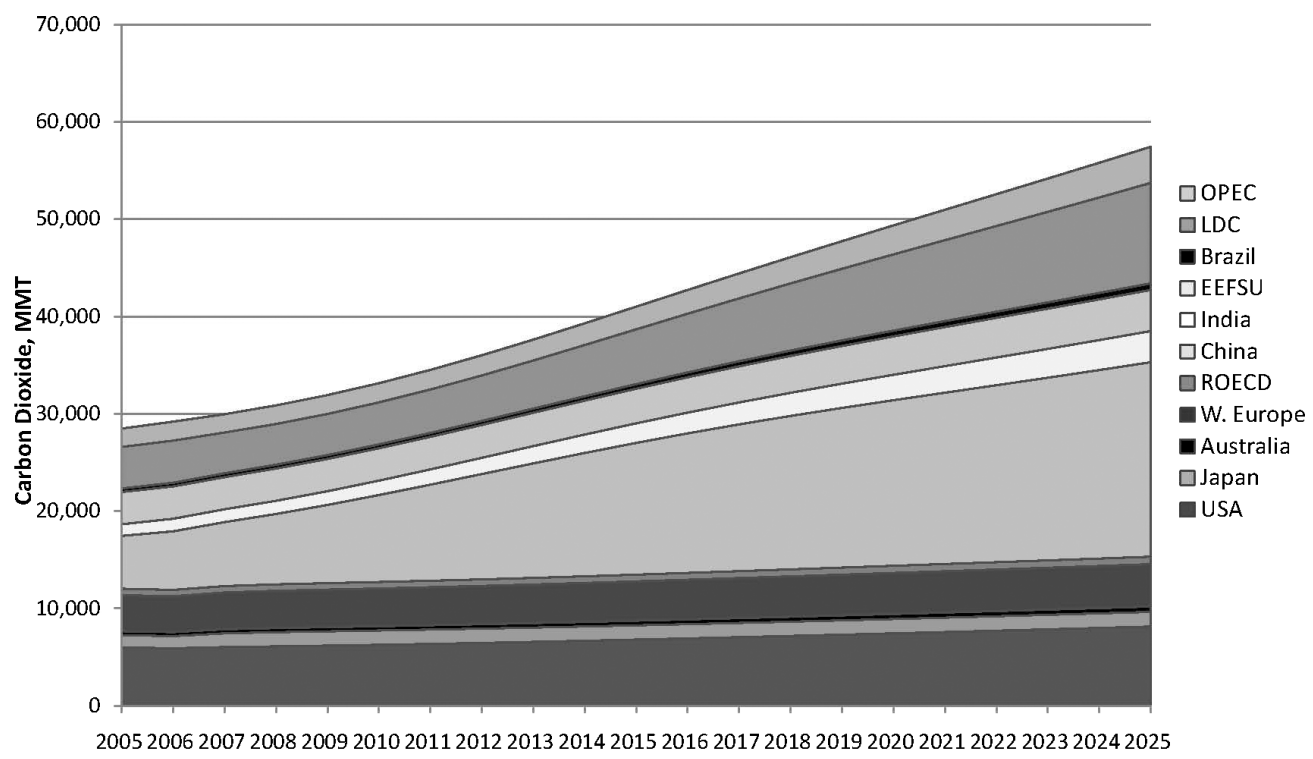

Year

Figure 1. Baseline scenario fossil $\mathrm{CO}_{2}$ emissions.

Figure 1 shows fossil $\mathrm{CO}_{2}$ emissions by region in the baseline scenario. Clearly the largest source of projected world emissions growth is China, although other developing countries also contribute an increasing share.

\subsection{The policy scenario}

In order to analyze the potential economic implications of Accord with a general equilibrium model, we must construct a policy scenario that specifies what countries do to achieve their commitments. This necessarily involves some simplifying assumptions. Our approach is to analyze a policy scenario in which all countries with targets adopt least cost abatement strategies. We assume that the Accord policy scenario begins in 2012, at which time the countries with economy-wide targets under the Copenhagen Accord place a price on all carbon dioxide emitted from fossil fuels. All countries achieve their targets domestically (i.e. with no offsets or emissions trading) by imposing an economy-wide price signal on carbon in 2012 that rises at a four percent real rate of interest such that the 2020 targets are met. Four percent represents an estimate of the risk-free rate of return that drives the optimal intertemporal choice of incurring abatement costs. ${ }^{6}$ A higher discount rate would result in lower estimated initial prices on emissions but faster growth.

We assume the emissions price rises through 2050 or until emissions fall to nearly zero, whichever comes first. When emissions fall to nearly zero, we hold the carbon

\footnotetext{
${ }^{6}$ McKibbin et al. (2009), p. 6, explains the connection between a price signal that rises at the real rate of interest and cost minimization.
} 
Table 3. Emissions targets for 2020 for the policy scenario.

\begin{tabular}{cccc}
\hline & Reduction percent & In emissions & Relative to \\
\hline USA & 17 & Level & 2005 \\
Japan & 25 & Level & 1990 \\
Australia & 5 & Level & 2000 \\
Europe & 20 & Level & 1990 \\
ROECD & 17 & Level & 2005 \\
China & 40 & Per Unit GDP & 2005 \\
India & 20 & Per Unit GDP & 2005 \\
EEFSU & 28 & Level & 1990 \\
\hline
\end{tabular}

price constant thereafter. We solve for the initial price on carbon in 2012 in each country such that it hits its target for 2020 as set out in Table 3.

For the Chinese and Indian commitments to reduce emissions per unit GDP, we assume the intensity targets refer to emissions per unit real GDP. This is an important assumption. Even without any other change in the economy or emissions, inflation reduces the emissions intensity measured in nominal terms.

Several aspects of this stylized policy scenario differ importantly from the policies countries might actually adopt. For example, the stipulation that all abatement is domestic could differ markedly from the actual implementations of the Accord. Legislation considered in the U.S. Congress in 2010 would have allowed a substantial share of domestic compliance using credits for certain emissions reductions ("offsets") achieved outside the energy sector (for example in forest carbon) or abroad. In this analysis, we exclude offsets for two reasons. First, we are modeling a simplified and stylized interpretation of the Accord commitments. Since the agreement is silent on emissions trading there is no clear way to anticipate the quantity or price of imported reductions that a country might use to comply with its commitments. Second, the policy scenario includes economy-wide targets for two of the largest potential sources of offsets, China and India. It is unclear how these economy-wide targets would be compatible with offset sales. ${ }^{7}$ To avoid double counting, only reductions outside energy or beyond the Copenhagen commitments would be eligible. To the extent that Accord participants meet some of their abatement requirements abroad or outside the energy sector, then they may lower the overall costs of their environmental accomplishments. On the other hand, if countries with targets adopt a policy that is less efficient than an economy-wide price on fossil carbon they may increase the overall cost of their goals relative to the policy scenario we specify.

We assume that the Accord does not allow over-compliance with targets under the Kyoto Protocol to allow under-compliance with the Accord targets. Within the EU capand-trade system, for example, some firms may have unused emissions allowances in

\footnotetext{
${ }^{7}$ Dellink et al. (2010) (p. 22) report that China and India supply the vast majority of offsets.
} 
2011 that they can use for domestic compliance in years after the Accord compliance period begins, but we assume that no such flexibilities apply at the country level.

We also assume the price signal and emissions targets in the policy scenario apply only to $\mathrm{CO}_{2}$ from fossil fuel consumption from the energy sector, including combustion of coal, natural gas, and oil. For example, if the target specifies a reduction of 17 percent below 2005 emissions levels by 2020 , then we compute a scenario in which $\mathrm{CO}_{2}$ emissions from the energy sector in 2020 are 17 percent lower than emissions from those same sources in 2005. Including other GHG sources in the analysis would result in potentially lower marginal abatement costs, but higher overall levels of abatement, with unclear net effect on costs relative to the results we present below.

$\mathrm{CO}_{2}$ from energy-related fossil fuel consumption includes a large majority of total U.S. greenhouse gas emissions and the vast majority of emissions growth since 2000 . For example, according to the U.S. Environmental Protection Agency, fossil fuel combustion comprised 94 percent of all U.S. $\mathrm{CO}_{2}$ emissions in 2007, and over 80 percent of total U.S. greenhouse gas emissions on a $\mathrm{CO}_{2}$-equivalent basis. ${ }^{8} \mathrm{In}$ addition, the increase in net growth in all U.S. GHG emissions from 2000 to 2007 came almost entirely from increases in $\mathrm{CO}_{2}$ from energy-related fossil fuel combustion. In fact, fossil energy $\mathrm{CO}_{2}$ emissions grew by 174 million metric tons from 2000 to 2007, but were partially offset by declines in other emissions for a net growth in all U.S. GHG's of 142 million metric tons of $\mathrm{CO}_{2}$ equivalent $\left(\mathrm{MMTCO}_{2} \mathrm{E}\right)$.

G-Cubed does not include a land use module, so we exclude consideration of terrestrial carbon in our analysis. As with non- $\mathrm{CO}_{2}$ gases, including land use and forestry sources and sinks could substantially alter the implications for the targets, but in what way is unclear. Some countries, such as the U.S., accrue carbon stocks each year in forests and agricultural soils, and some countries such as Australia produce positive net emissions from terrestrial ecosystems. The Accord Appendix I lists "quantified economy-wide emissions targets," without specifying whether or not they are net of terrestrial carbon sources/sinks. Counting land use emissions fully could not only change the stringency of the targets but also change the marginal abatement costs to meet it relative to an approach that includes only fossil fuel-related $\mathrm{CO}_{2}$. Further, even if negotiators eventually agree to include some terrestrial carbon stocks, they may not include all of them. Heated debate accompanied such accounting rules under the Kyoto Protocol and will likely arise again if the Accord moves towards binding status.

Like most global economic models, due to computational constraints G-Cubed groups some countries into composite regions based on geography and the degree of economic development. This means that to model the targets of the Copenhagen Accord, we must ascribe targets to these regional groupings that reasonably reflect the commitments of the individual countries in the group. By definition, this modeling scenario will not be identical to a scenario in which each country in the group achieves

${ }^{8}$ U.S. Environmental Protection Agency (2009), p. ES-4, Table ES-2. Figures do not account for carbon stored in terrestrial carbon sinks. 
its own independent target. For example, we apply a target for the "Rest of the OECD" region (17 percent below 2005 levels) that equals the Accord target of Canada, the largest economy in that group. We set the target for Western Europe to the EU's Accord target of 20 percent below 1990 levels, and apply Russia's Copenhagen target of 15 percent below 1990 emissions levels to G-Cubed's EEFSU region. The two regional groupings of Western Europe and EEFSU do not correspond exactly to the groups of countries taking commitments under the Copenhagen Accord. In particular, the European Union member countries include some countries in Eastern Europe, which fall in EEFSU. For EEFSU, we apply Russia's much less stringent target of 15 percent relative to 1990 levels.

We assume all participating countries act in concert, which means the policy scenario accounts for the higher price signals necessary to achieve the targets when world energy prices fall as a result of declining global demand. Where countries offered a range of potential Accord targets that depend on what other countries do, we assume they achieve the least stringent target they have offered.

We assume that each of the non-OECD regions in our model that have not promised economy-wide targets (Brazil, Other LDC's, and OPEC) do not adopt an economywide price on carbon through the duration of the analysis. Indonesia, Brazil, and others committed to substantial decreases in deforestation and other land-related emissions, but these commitments may have little effect on the fossil-fuel related $\mathrm{CO}_{2}$ that is the focus of this study. Brazil committed under the Accord to a total of eleven sectorspecific measures and targets. It anticipates these proposed measures will reduce its emissions in 2020 by about 36 to 39 percent relative to (unspecified) baseline projections. However, because Brazil has committed to the actions rather than the projected emissions outcomes, the policy scenario for this analysis treats Brazil as not adopting an economy-wide emissions target or price on carbon.

With these simplifying assumptions, we estimate and compare the overall costs, price signals, and emissions outcomes of the agreement.

\section{Comparing the Commitments in Common Terms}

This section explores the Copenhagen commitments in common terms in several dimensions, including as changes in emissions levels, changes in emission intensity (emissions per unit GDP), and changes in per capita emissions.

\subsection{Emissions levels}

Using the baseline and policy scenarios described in Sec. 2, we can convert the disparate targets under the Accord into common formulations. Table 4 and Fig. 2, report the Copenhagen Accord emissions commitments for 2020 in common historical base years $(1990,2000$, and 2005) and relative to emissions in the 2020 baseline scenario, or business as usual (BAU) emissions. For China and India, commitments are reported 
Table 4. Emissions in 2020 that result from Copenhagen Accord.*

\begin{tabular}{crrrr}
\hline & $\begin{array}{r}2020 \\
\text { Target as a percent change in emissions in 2020 } \\
\text { relative to emissions in the indicated year }\end{array}$ \\
\hline Country & 1990 & 2000 & 2005 & BAU in 2020 \\
\hline USA & -1 & -15 & $-\mathbf{1 7}$ & -33 \\
Japan & $-\mathbf{2 5}$ & -37 & -39 & -48 \\
Australia & 30 & $-\mathbf{5}$ & -18 & -35 \\
Europe & $-\mathbf{2 0}$ & -24 & -27 & -36 \\
ROECD & 10 & -7 & $-\mathbf{1 7}$ & -25 \\
China & 496 & 350 & 146 & -22 \\
India & 346 & 159 & 120 & 0.4 \\
EEFSU & $-\mathbf{1 5}$ & 28 & 18 & -1.3 \\
Brazil & 168 & 73 & 61 & 0.6 \\
LDC & 211 & 119 & 85 & 0.9 \\
OPEC & 180 & 105 & 60 & 1.3 \\
World & 90 & 70 & 43 & -17.5 \\
\hline
\end{tabular}

*Boldface numbers represent the commitment formulas in the Copenhagen Accord. Negative numbers are reductions, and positive numbers are increases relative to the base year.

using the emissions levels in 2020 that produces the targeted reductions in emissions per unit real GDP. For the regions without Accord targets (Brazil, LDC, and OPEC), emissions in the policy scenario are measured against their historical emissions and BAU projections for 2020.

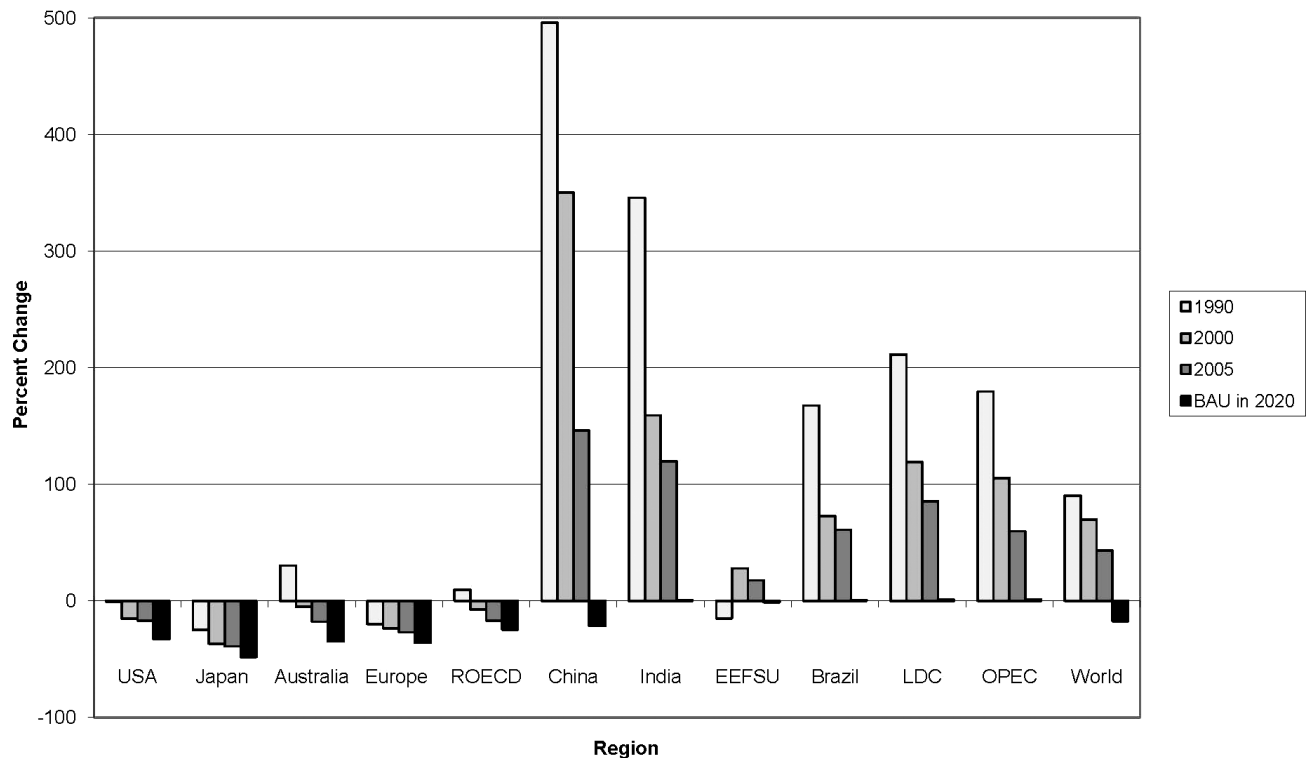

Figure 2. 2020 Policy scenario emissions levels relative to different base years. 
Table 4 shows that regional emissions results range from an increase of 1.3 percent relative to baseline in OPEC to a decline of 48 percent in Japan. Our estimates of the stringency of 2020 targets relative to BAU emissions are most consistent with the high growth scenario estimates in Jotzo (2010). This suggests that our estimates of the carbon prices necessary to achieve the Accord targets may be higher than other studies' because our model predicts relatively high baseline emissions growth.

As might be expected, emissions increase relative to baseline in regions without targets as they experience lower fossil energy prices and inflows of investment. This increase is called "emissions leakage." We find that emissions leakage is less than two percent of baseline emissions in the regions without economy-wide targets. The net result of the changes that result from the Accord is a decline in world emissions of more than 17 percent relative to baseline in 2020. In practice, fossil fuel-related emissions leakage and global emissions generally will depend on the effectiveness of mitigation actions in the developing world and the ultimate effect of the agreement on fuel prices.

Table 4 reveals how the formula for the target affects its apparent stringency. In particular, it shows how reductions relative to historical base years bear little relation to reductions relative to business as usual. For example, the model suggests that China's emissions goal under the Accord implies a nearly five-fold increase in emissions relative to 1990 levels, but the target still represents a 22 percent departure from Chinese baseline emissions in 2020, nearly as ambitious as the 25 percent reductions from baseline by the ROECD countries. EEFSU's 15 percent reduction relative to 1990 levels represents about a one percent decline relative to BAU.

Table 5 reinterprets the results for Accord participants in Table 4. For each base year, it ranks the regions' commitments relative to each other, with a rank of one for the region with the greatest percent emissions reductions and the rank of eight for the region with the lowest percent emissions reductions.

Table 5. Ranking of participants by reductions in emissions levels.*

\begin{tabular}{ccccc}
\hline Rank & $\begin{array}{c}\text { Change relative } \\
\text { to } 1990 \text { base } \\
\text { year emissions }\end{array}$ & $\begin{array}{c}\text { Change relative } \\
\text { to 2000 base } \\
\text { year emissions }\end{array}$ & $\begin{array}{c}\text { Change relative } \\
\text { to 2005 base } \\
\text { year emissions }\end{array}$ & $\begin{array}{c}\text { Change from } \\
\text { 2020 BAU } \\
\text { emissions }\end{array}$ \\
\hline 1 & Japan & Japan & Japan & Japan \\
2 & Europe & Europe & Europe & Europe \\
3 & EEFSU & USA & Australia & Australia \\
4 & USA & ROECD & USA/ROECD & USA \\
5 & ROECD & Australia & EEFSU & ROECD \\
6 & Australia & EEFSU & China \\
7 & India & India & India & EEFSU \\
8 & China & China & China & India \\
\hline
\end{tabular}

*Boldface entries in the table show the commitment base years in the Copenhagen Accord. 
Tables 4 and 5 show that of all the modeled regions, Japan pursues the largest emissions reduction commitment relative to all base years. Japan's target for 2020 is almost half its baseline emissions. Western Europe, Australia, and the U.S. committed to similar departures from BAU with projected emissions declines by 2020 of 36, 35, and 33 percent respectively. Table 4 shows that India's commitment to reduce by 20 percent relative to 2005 its emissions per unit GDP implies a 356 percent increase in emissions levels from 1990 but close to baseline emissions levels in 2020 .

Table 5 illustrates the negotiating complications if countries must agree on a common base year but each country has the incentive to pick a base year that makes it look most stringent relative to its peers. For example, Australia ranks sixth with a 1990 base year, but rises to third in ambition relative to BAU. Likewise, the EEFSU's commitment means minimal reductions relative to baseline but ranks third in the 1990 roster. The rankings of commitments by Japan and the EEFSU do not vary by formulation. The boldface cells in Table 5 show that when given flexibility in its commitment formulation, not all countries choose the approach that maximizes their rank. Australia would have looked more ambitious relative to its peers had it chosen a 2005 base year, and the U.S. would have ranked higher with a 2000 base year formulation.

\subsection{Other measures of emissions reductions}

Table 6 shows the emissions outcomes of Table 4 recast in terms of emissions per unit GDP, or emissions intensity. To calculate emissions intensity, we divide emissions levels by historical data for real GDP for the 1990, 2000, and 2005 base years and projected GDP for 2020, all in 2006 US dollars. The second column in Table 6 is emissions intensity in 2020 in the baseline and the third column is the same measure under the policy scenario. Column 4 of Table 6 shows that emissions intensity declines from 2005 to 2020 in all regions in the baseline, with the greatest decline of 37 percent in Brazil. Accord participation accelerates those declines.

The sixth column of Table 6 shows the percent change in intensities in the policy scenario relative to the 2020 baseline. Overall, world emissions relative to world GDP declines by 15 percent as a result of the Accord. The relative ambition by different countries is similar to the ambition in emissions levels reflected in Table 4. Again Japan is undertaking the most ambitious commitment with an intensity decline of 46 percent relative to baseline by 2020. Japan is significantly more ambitious than the next most ambitious countries, Western Europe, the U.S., and Australia, with intensity declines of 33, 31, and 30 percent respectively. Table 6 also shows that China's intensity target results in substantial intensity reductions relative to baseline (18 percent), on par with the 20 percent intensity reductions of developed countries in ROECD.

Table 7 shows the emissions commitments from Table 6 expressed in per capita terms. This table reveals that on a per capita basis, Japan will lower its emissions per capita relative to baseline the most, by 48 percent. 
Table 6. Copenhagen Accord emissions commitments in intensity terms.*

\begin{tabular}{|c|c|c|c|c|c|c|}
\hline & 1 & 2 & 3 & 4 & 5 & 6 \\
\hline Region & $\begin{array}{l}\text { Emissions } \\
\text { intensity } \\
\text { in } 2005 \\
\left(\mathrm{MMTCO}_{2} /\right. \\
\text { \$2006GDP) }\end{array}$ & $\begin{array}{l}\text { Baseline } \\
\text { emissions } \\
\text { intensity } \\
\text { in } 2020 \\
\left(\mathrm{MMTCO}_{2} /\right. \\
\text { \$2006GDP) }\end{array}$ & $\begin{array}{l}\text { Emissions } \\
\text { intensity in } \\
2020 \text { under } \\
\text { Accord }\end{array}$ & $\begin{array}{l}\text { Percent } \\
\text { change in } \\
\text { intensity } \\
\text { from } 2005 \\
\text { to } 2020 \text { in } \\
\text { baseline }\end{array}$ & $\begin{array}{l}\text { Percent } \\
\text { change in } \\
\text { intensity } \\
\text { from } 2005 \text { to } \\
2020 \text { under } \\
\text { Copenhagen } \\
\text { Accord }\end{array}$ & $\begin{array}{c}\text { Percent change in } \\
2020 \text { emissions } \\
\text { intensity relative } \\
\text { to BAU }\end{array}$ \\
\hline USA & 0.47 & 0.38 & 0.26 & -18 & -44 & -31 \\
\hline Japan & 0.28 & 0.27 & 0.15 & -3 & -47 & -46 \\
\hline Australia & 0.56 & 0.45 & 0.31 & -20 & -44 & -30 \\
\hline Europe & 0.27 & 0.21 & 0.14 & -20 & -46 & -33 \\
\hline ROECD & 0.53 & 0.38 & 0.30 & -28 & -43 & -20 \\
\hline China & 2.35 & 1.73 & 1.41 & -26 & -40 & -18 \\
\hline India & 1.40 & 1.13 & 1.12 & -20 & -20 & 0 \\
\hline EEFSU & 1.61 & 1.20 & 1.22 & -26 & -25 & 2 \\
\hline Brazil & 0.40 & 0.25 & 0.25 & -37 & -37 & 1 \\
\hline LDC & 0.76 & 0.49 & 0.50 & -35 & -34 & 1 \\
\hline OPEC & 1.12 & 0.91 & 0.98 & -18 & -12 & 8 \\
\hline World & 0.61 & 0.58 & 0.49 & -5 & -19 & -15 \\
\hline
\end{tabular}

*Boldface numbers represent commitments as articulated in the Copenhagen Accord.

Table 7. Copenhagen Accord emissions commitments in per capita terms.

\begin{tabular}{ccccc}
\hline & 1 & 2 & 3 & 4 \\
\hline Region & $\begin{array}{c}\text { Emissions per } \\
\text { capita in 2005 }\end{array}$ & $\begin{array}{c}\text { Emissions per } \\
\text { capita in 2020 in } \\
\text { baseline }\end{array}$ & $\begin{array}{c}\text { Emissions per } \\
\text { capita in 2020 } \\
\text { under Accord }\end{array}$ & $\begin{array}{c}\text { Change in 2020 } \\
\text { per capita emis- } \\
\text { sions relative to } \\
\text { BAU }\end{array}$ \\
\hline USA & & & & -33 \\
Japan & 10 & 22 & 15 & -48 \\
Australia & 21 & 12 & 6 & -35 \\
Europe & 12 & 23 & 15 & -36 \\
ROECD & 18 & 14 & 9 & -25 \\
China & 4 & 18 & 14 & -22 \\
India & 1 & 13 & 10 & -1 \\
EEFSU & 11 & 2 & 2 & 1 \\
Brazil & 2 & 14 & 14 & 1 \\
LDC & 2 & 3 & 2 & -17 \\
OPEC & 8 & 2 & 11 & 1 \\
World & 4 & 10 & 5 & \\
\hline
\end{tabular}




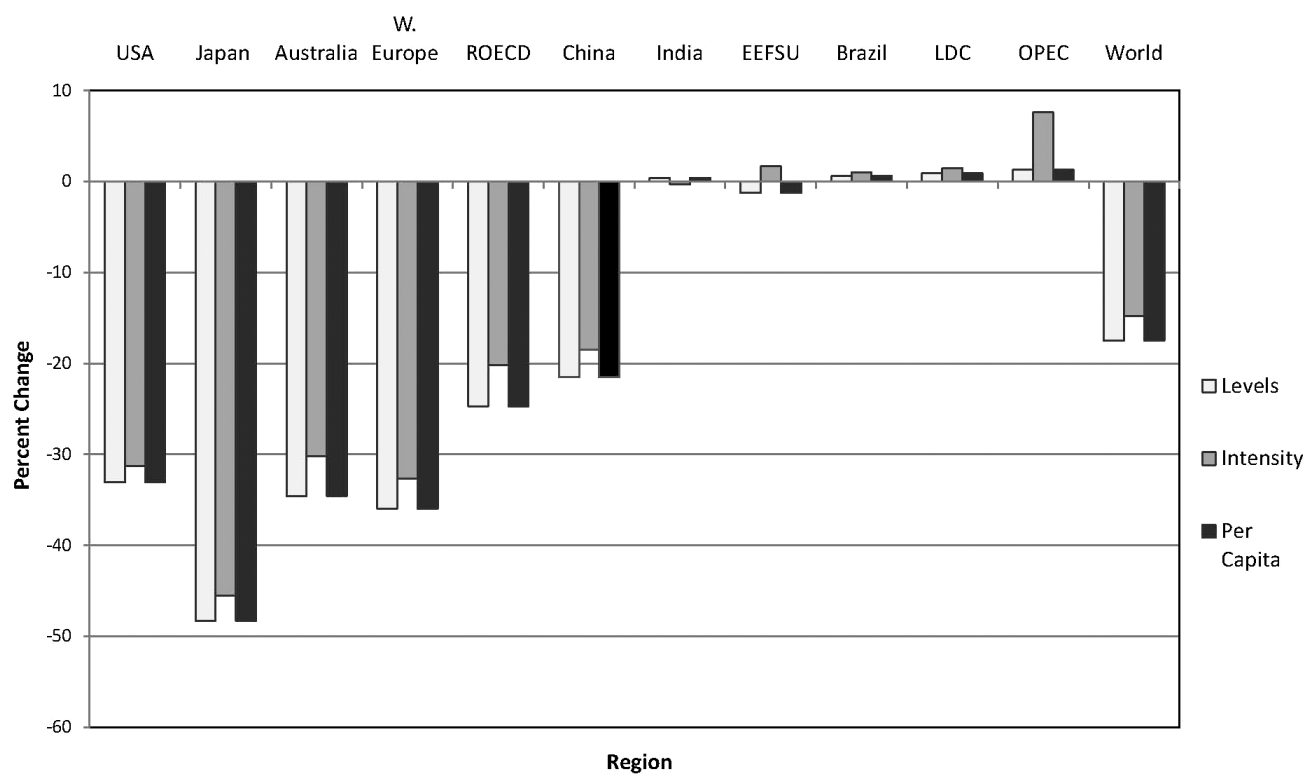

Figure 3. Percent change in 2020 emissions relative to baseline.

Figure 3 and Table 8 summarize the ranking of emissions reductions reflected in the Copenhagen target in level, intensity, and per capita terms. Figure 3 shows that by all measures Japan reports the greatest emissions declines. Of regions with Accord targets, India and EEFSU are the least ambitious across all measures. The U.S. is within a few percentage points of Western Europe and Australia, followed by the ROECD and China. We find small effects of the Accord in India, Brazil, EEFSU, and other LDCs. Consistent with its energy intensive economy and not having price on carbon, emissions intensity rises in OPEC relative to baseline.

Table 8. Ranking of participants by reductions in different emissions measures.

\begin{tabular}{cccc}
\hline Rank & $\begin{array}{c}\text { Change in 2020 emissions } \\
\text { levels relative to BAU }\end{array}$ & $\begin{array}{c}\text { Change in 2020 emissions } \\
\text { intensity relative to BAU }\end{array}$ & $\begin{array}{c}\text { Change in 2020 per capita } \\
\text { emissions relative to BAU }\end{array}$ \\
\hline 1 & Japan & Japan & Japan \\
2 & Europe & Europe & Europe \\
3 & Australia & USA & Australia \\
4 & USA & Australia & USA \\
5 & ROECD & ROECD & ROECD \\
6 & China & China & China \\
7 & EEFSU & India & EEFSU \\
8 & India & EEFSU & India \\
\hline
\end{tabular}




\section{Environmental and Economic Outcomes of the Copenhagen Targets}

To assess how climate policy might affect outcomes of interest, we compare the values of economic and environmental variables in the policy scenario to their values in the reference scenario. This section looks beyond different measures of the target 2020 reductions in Section 3 to examine longer term environmental effects and the burdens countries incur to achieve them. As before, we focus on outcomes as percentage changes from reference.

Figure 4 shows fossil $\mathrm{CO}_{2}$ emissions by region in the policy scenario. This stacked graph shows a marked departure from the analogous baseline graph, Fig. 1. The sharp decline in the policy scenario emissions in 2012 reflects the imposition in 2012 of the price signal by Accord participants. The graphs indicate that world emissions are almost $10,000 \mathrm{MMTCO}_{2}$ lower in 2020 than in the baseline scenario.

Figure 5 shows emissions relative to baseline through 2025, and Table 9 shows the percentage change in each country's cumulative emissions between 2013 and 2020. For reference, the percentage changes in 2020 emissions from Table 7 are shown as well. Because Annex I policies become increasingly stringent over time, cumulative reductions for those countries are somewhat smaller in percentage terms than their 2020 commitments. Cumulative U.S. emissions, for example, are 27 percent below the reference case while 2020 emissions are 33 percent lower. These results are sensitive to the simplifying policy assumptions we have made. For example, the cumulative emissions reductions in Table 9 are closer to 2020 reductions than would be the case under a policy scenario that enforced a linear decline in emissions levels rather than the particular increasing real price path we specified.

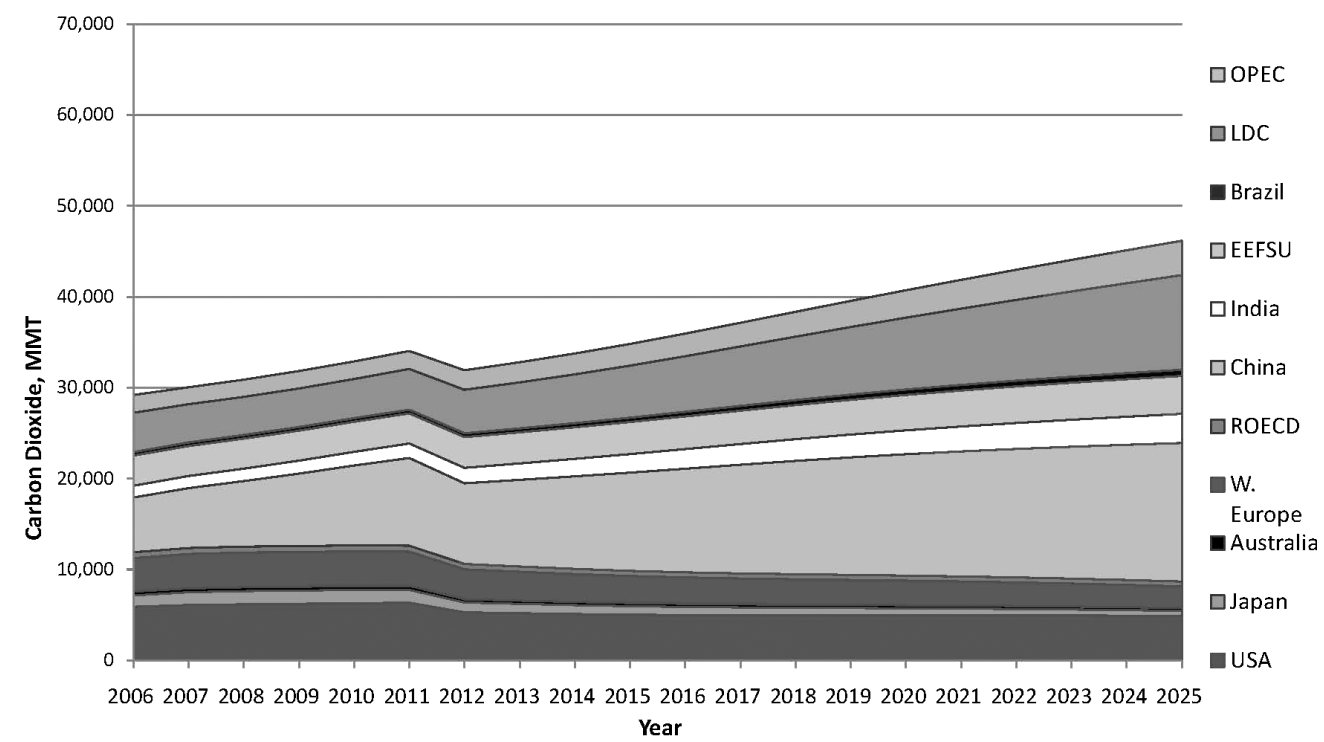

Figure 4. Policy scenario fossil $\mathrm{CO}_{2}$ emissions. 


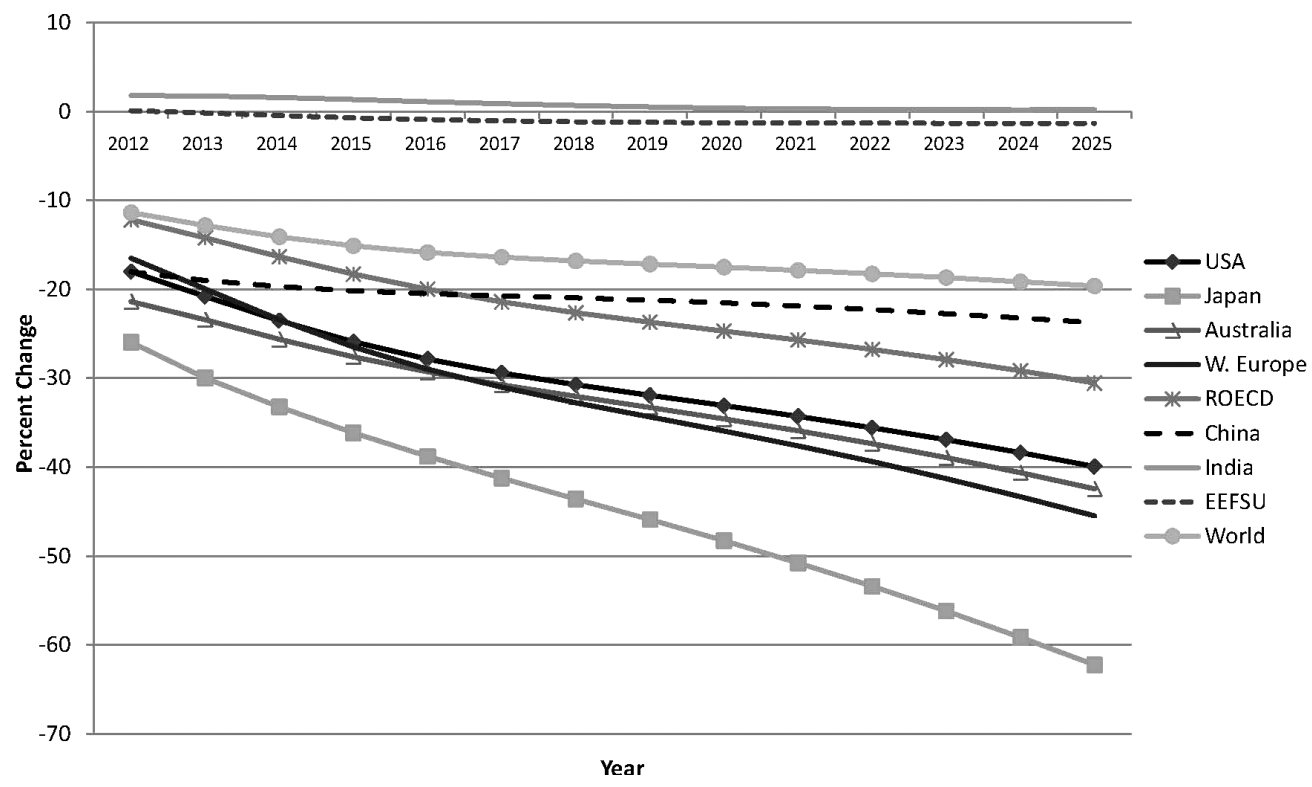

Figure 5. $\mathrm{CO}_{2}$ emissions relative to baseline.

The economic consequences of the Accord vary significantly between countries. Table 10 provides several measures of the effects of each country's commitment. The first two columns provide a measure of the marginal cost of the Accord: $\mathrm{CO}_{2}$ prices in U.S. dollars per ton of carbon dioxide in 2012 and 2020. Figure 6 shows the trajectory of $\mathrm{CO}_{2}$ prices in the relevant regions. Measured in these terms, the Accord's stringency is highest in Europe and Japan, both of which have 2012 prices above $\$ 50$ per ton.

Table 9. Emissions outcomes of Copenhagen Accord.

\begin{tabular}{ccc}
\hline Region & $\begin{array}{c}\text { Percent change in } \\
\text { 2020 emissions } \\
\text { levels relative to } \\
\text { BAU }\end{array}$ & $\begin{array}{c}\text { Percent change in } \\
\text { cumulative emissions, } \\
2013 \text { to 2020, relative } \\
\text { to BAU }\end{array}$ \\
\hline USA & -33 & -27 \\
Japan & -48 & -38 \\
Australia & -35 & -29 \\
Europe & -36 & -28 \\
ROECD & -25 & -19 \\
China & -22 & -20 \\
India & 0 & 1 \\
EEFSU & -1 & -1 \\
Brazil & 1 & 1 \\
LDC & 1 & 1 \\
OPEC & 1 & 2 \\
World & -17 & -15 \\
\hline
\end{tabular}


Table 10. Economic outcomes of Copenhagen Accord.

\begin{tabular}{|c|c|c|c|c|c|}
\hline Region & $\begin{array}{l}\text { Economy-wide } \\
2012 \text { price per } \\
\text { ton } \mathrm{CO}_{2}(\$ 2006)\end{array}$ & $\begin{array}{l}\text { Economy-wide } \\
2020 \text { price per } \\
\text { ton } \mathrm{CO}_{2}(\$ 2006)\end{array}$ & $\begin{array}{l}\text { Percent change } \\
\text { in } 2020 \mathrm{GDP} \\
\text { relative to BAU }\end{array}$ & $\begin{array}{l}\text { Percent change } \\
\text { in } 2020 \\
\text { consumption } \\
\text { relative to BAU }\end{array}$ & $\begin{array}{l}\% \text { Change in } \\
\text { discounted } \\
\text { cumulative } \\
\text { consumption } \\
\text { (2012-2020) } \\
\text { relative to BAU }\end{array}$ \\
\hline USA & $\$ 28.09$ & $\$ 38.44$ & -2.7 & 0.0 & 0.9 \\
\hline Japan & $\$ 50.36$ & $\$ 68.92$ & -5.1 & -3.1 & -2.0 \\
\hline Australia & $\$ 15.91$ & $\$ 21.78$ & -6.3 & -2.0 & -1.4 \\
\hline Europe & $\$ 56.76$ & $\$ 77.68$ & -4.9 & -3.1 & -1.8 \\
\hline ROECD & $\$ 18.06$ & $\$ 24.72$ & -5.6 & -3.9 & -3.0 \\
\hline China & $\$ 15.22$ & $\$ 20.82$ & -3.7 & -4.5 & -2.8 \\
\hline India & $\$ 1.02$ & $\$ 1.40$ & 0.7 & 1.6 & 2.3 \\
\hline EEFSU & $\$ 0.95$ & $\$ 1.30$ & -2.9 & -3.4 & -2.6 \\
\hline Brazil & - & - & -0.4 & -0.5 & -0.1 \\
\hline LDC & - & - & -0.6 & -0.5 & 0.2 \\
\hline OPEC & - & - & -5.9 & -13.2 & -12.1 \\
\hline World & - & - & -3.2 & -2.1 & -1.0 \\
\hline
\end{tabular}

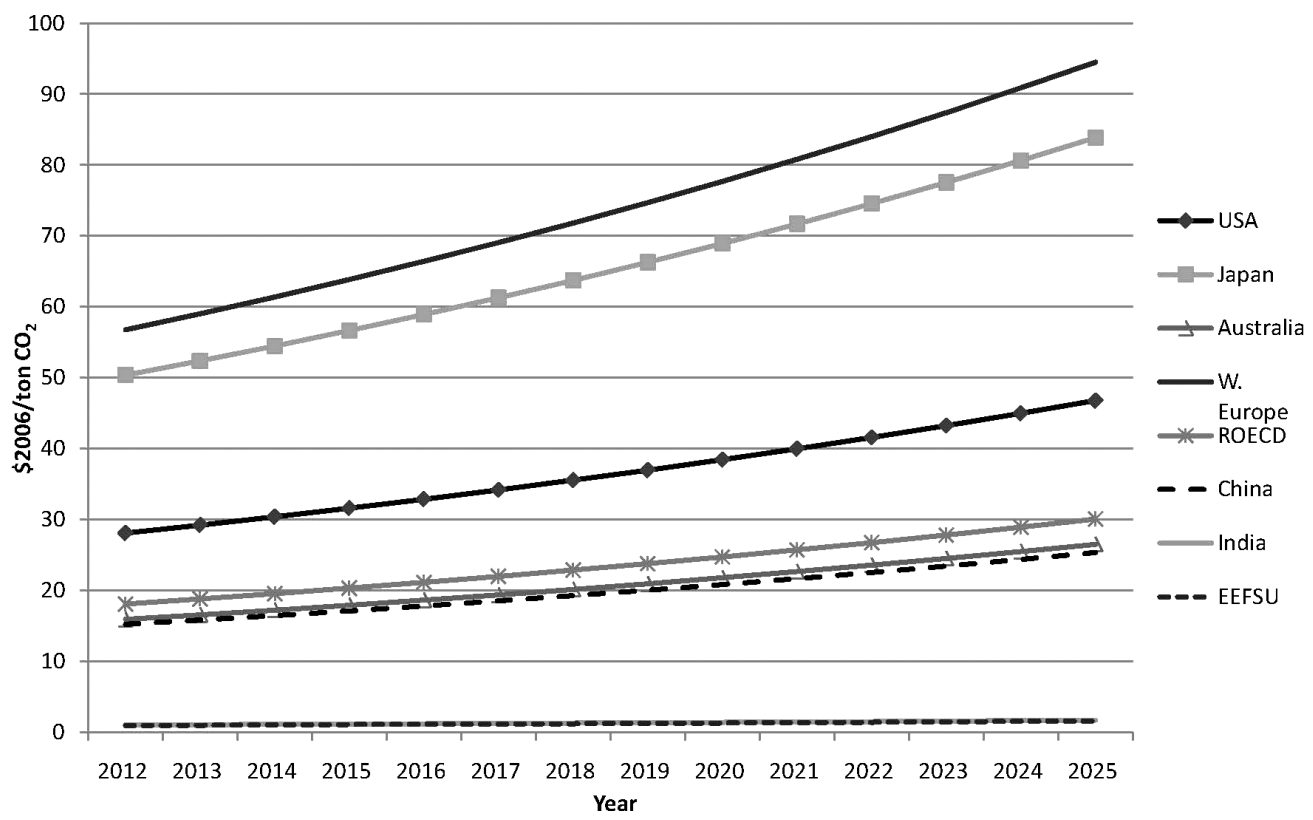

Figure 6. Price per metric ton of $\mathrm{CO}_{2}$.

Next in order of stringency is the U.S., with a $2012 \mathrm{CO}_{2}$ price of $\$ 28$. Somewhat lower are Australia, China and ROECD, all of which have $2012 \mathrm{CO}_{2}$ prices below $\$ 20$ per ton. Finally, India and EEFSU have the substantially lower stringency with 2012 prices around $\$ 1$ per ton. By 2020, $\mathrm{CO}_{2}$ prices in all regions are 37 percent larger, 
reflecting the four percent real rate of growth imposed in the simulation. The relative stringency between countries - measured in terms of $\mathrm{CO}_{2}$ prices - is identical to that in 2012 .

Our estimated carbon prices are substantially higher than those estimated by Dellink et al. (2010). Their study does not include enough information to explain the difference precisely, but our relatively high baseline emissions trajectories and our assumption that countries do not engage in emissions trading or offset markets play important roles. For example, Dellink et al. show that in a scenario in which countries achieve the most stringent end of their range of pledged targets, allowing offsets of about $20 \%$ of compliance reduces the carbon price by about one quarter.

The three right-most columns in Table 10 provide alternative measures of economic effects of the Accord. They report the effects on real GDP and consumption in 2020, and on the present value of consumption from 2012 to 2020, all as percentage changes relative to the reference case. By this measure, India actually gains slightly (about one percent). GDP declines in other regions with the largest effects in Australia, ROECD and OPEC (reductions of roughly six percent), followed by slightly smaller effects in Japan and Europe (about five percent), then China (about four percent), the United States and EEFSU (about three percent), and finally Brazil and LDCs (reductions of about one percent).

We emphasize that these results reflect reductions relative to the 2020 reference case. In other words, the Accord slows GDP growth, but GDP generally increases from year to year from 2012 to 2020 , even in the regions where the policy impacts are largest. The drop in the average annual growth rate ranges from 0.1 to 0.3 percentage points, with the largest reductions in Japan and Western Europe. The decline for the U.S. is 0.23 percentage points. That is, the average annual U.S. growth rate from 2012 to 2020 declines from 2.66 to 2.43 percent as a result of global greenhouse efforts. This means that under the policy scenario, in 2020 the U.S. GDP would be 22 percent larger than in 2012 rather than the baseline projection of 25 percent larger. The U.S. result is characteristic of most other regions. The one exception to this broad pattern appears in Japan, which has relatively slow baseline GDP growth. Japanese GDP drops slightly from 2012 to 2013 under the Accord, and then rises consistently thereafter.

Note that the ordering of regions by marginal cost differs significantly from the ordering by GDP effect. For some countries, GDP effects tend to mirror price effects: Japan and Europe have high carbon prices and are among the highest in terms of GDP effects; the United States and China both have moderate carbon prices and moderate GDP effects; and Brazil and the LDCs have zero carbon prices and low GDP effects. In contrast, Australia, ROECD and EEFSU have relatively large GDP effects despite having small or zero carbon prices. For these regions, the GDP effect is exacerbated by strengthening of the U.S. dollar and capital flows out of these regions into the United States. OPEC also suffers a large drop in GDP relative to the reference case (5.9 percent) although in its case the effect is simply due to a sharp decline in the world demand for oil. Finally, India's terms of trade improve as a result of the Accord and its GDP rises slightly even though it imposes a small price on carbon. 
In terms of consumption, the Accord separates the regions into roughly three groups: the developed countries, which have smaller 2020 declines in consumption than in GDP; the developing and transition economies, in which GDP and consumption effects are roughly similar; and OPEC, for which the 2020 decline in consumption is far larger than the contemporaneous decline in GDP. Developed country consumption declines less than GDP in part because the commitments in the Accord raise energy prices enough to induce substantial conservation, which leads to reductions (relative to the reference case) in the output of the energy sectors and the investment needed for new mining and electrical generation capital. In addition, the effect on consumption is also moderated by improvements in the terms of trade of countries formerly importing large amounts of crude and refined petroleum.

The final column in Table 10 shows the effect of the Accord on the discounted present value of consumption. The results parallel the changes in 2020 consumption but are lower in magnitude for the same reason that cumulative changes in emissions are lower than 2020 changes: the policies are phased in gradually over time. A concise comparison of the economic effects of the Accord is shown in Table 11.

Our goal here is to assess the broad ambition of the commitments in the Accord independent of the as-yet-unwritten rules that will elaborate how they might be achieved. That said, both the emissions and economic outcomes discussed above are importantly dependent on the business-as-usual scenario in our model and the assumptions embedded in the policy scenario. If economic growth is higher (lower) than predicted in the model, the targets would involve accordingly higher (lower) emissions reductions and costs.

We do not include a number of features that may be part of an eventual binding agreement and would influence the pattern of effects across countries, including: international emissions trading, domestic and international offset programs, non- $\mathrm{CO}_{2}$ greenhouse gases, changes in land use and forestry, or direct financial and

Table 11. Rankings of Accord burden by economic outcome.

\begin{tabular}{cccc}
\hline Rank & $\begin{array}{c}2012 \text { price } \\
\text { on } \mathrm{CO}_{2}\end{array}$ & $\begin{array}{c}\text { Rank in GDP } \\
\text { losses in 2020 }\end{array}$ & $\begin{array}{c}\text { Rank in consumption } \\
\text { losses in 2020 }\end{array}$ \\
\hline 1 & Europe & Australia & OPEC \\
2 & Japan & OPEC & ROECD \\
3 & USA & ROECD & China \\
4 & ROECD & Japan & EEFSU \\
5 & Australia & Europe & Japan \\
6 & China & China & Europe \\
7 & India & EEFSU & Australia \\
8 & EEFSU & USA & Brazil \\
9 & & LDC & LDC \\
10 & & Brazil & USA \\
11 & & India & India \\
\hline
\end{tabular}


technological transfers from the developed world to developing countries. Under international emissions trading, each participant would be responsible for meeting its announced target but high-cost countries would be able to substitute low cost reductions abroad for higher cost domestic abatement. Total emissions of participating countries would be the same as the policy scenario modeled here but trading would lead to a single international carbon price and would minimize the overall cost of attaining the joint goal of the participants. The pattern of emissions reductions across countries would differ, as would the economic effects and potentially the effects in nonparticipating countries as well. The wide spread of carbon dioxide prices illustrated in Fig. 6 suggests substantial potential gains from international exchanges that would induce more abatement in lower cost areas in exchange for less abatement in higher cost areas.

The outcome of a scenario combining the Copenhagen commitments with offset programs, including domestic and international land use and forestry activities, is harder to predict. By allowing additional compliance options, abatement in high cost regions and sectors would be lower, so overall costs (and therefore carbon price predictions) would be lower. However, the specific rules governing offsets including the incremental abatement that can be induced through offsets, the actual environmental performance of offsets, and transactions costs involved - would strongly influence the pattern of emissions and economic effects across countries.

\section{Conclusion}

The Copenhagen Accord marked the beginning of a new approach to international climate agreements. Previously, each round of negotiations generally adopted a fixed base year against which emissions commitments were to be measured and participating countries then negotiated a set of reductions relative to emissions in that year. The Accord breaks away from that approach by allowing each country to choose its own base year and to express its commitment in terms other than absolute reductions in emissions. This flexibility promoted consensus and allowed an agreement to be reached. At the same time, however, it complicates comparing the emissions reductions and economic efforts implicit in the commitments made by the participants.

In this paper, we have provided such a comparison using the G-Cubed model of the global economy. Our results show that alternative ways of expressing a commitment can make a single set of targets appear strikingly different in stringency. Moreover, we show that the actual stringency of the Accord, as measured by either GDP or consumption loss relative to a reference case, differs sharply across countries. This is because the economic consequences of each target depend importantly on a number of factors: the size of each country's economy in 2020; the internal structure of its economy; the extent to which carbon-intensive energy sources are a critical part of the energy system in 2020; the endowment of fossil fuels in each economy; and the ease or difficulty of substituting energy sources of energy intensive goods in production and 
consumption bundles. All of these factors affect the ambition embodied in the Accord's commitments.

Finally, we also find that for many countries the domestic price on carbon is a poor predictor of the welfare implications of the overall agreement. For example, the U.S. has the third highest carbon price but nearly no loss of consumption. On the other hand, OPEC has no price on carbon and experiences profound consumption losses because other countries are taxing OPEC exports and reducing global demand for these goods. The effect on OPEC suggests that the member countries would have an incentive to collectively raise world fuel prices if they can rather than suffer large losses in their terms of trade.

\section{Acknowledgments}

We gratefully acknowledge assistance from the U.S. Department of Energy. McKibbin acknowledges support from ARC Discovery Grant DP0988281. We thank Alison Stegman for technical support and Yiyong Cai, Hyejin Park and Waranya Pim Chanthapun for excellent research assistance. The views expressed in the paper are those of the authors and should not be interpreted as reflecting the views of any of the above collaborators or of the institutions with which the authors are affiliated including the trustees, officers or other staff of the Australian National University, Syracuse University, or Brookings.

\section{Appendix I. Country Composition of Regions in the G-Cubed Model}

\begin{tabular}{lcc}
\hline Region number & Region name & Region description \\
\hline 1 & USA & United States \\
2 & Japan & Japan \\
3 & Australia & Australia \\
4 & Europe & Western Europe \\
5 & ROECD & Rest of the OECD \\
7 & China & China \\
8 & India & India \\
9 & EEFSU & Eastern Europe and the former Soviet Union \\
10 & Brazil & Brazil \\
11 & LDC & Other Developing Economies \\
12 & OPEC & Oil Exporting Developing Countries \\
\hline
\end{tabular}

Western Europe: Germany, France, Italy, Spain, Netherlands, Belgium, Luxemburg, Ireland, Greece, Austria, Portugal, Finland, United Kingdom, Norway, Sweden, Switzerland, Denmark, Iceland, Liechtenstein.

Rest of OECD: Canada, New Zealand. 
Oil-exporting and the Middle East: Ecuador, Nigeria, Angola, Congo, Iran, Venezuela, Algeria, Libya, Bahrain, Iraq, Israel, Jordan, Kuwait, Lebanon, Palestinian Territory, Oman, Qatar, Saudi Arabia, Syrian Arab Republic, United Arab Emirates, Yemen.

Eastern Europe and Former Soviet Union: Albania, Armenia, Azerbaijan, Bulgaria, Belarus, Cyprus, Czech Republic, Estonia, Georgia, Croatia, Hungary, Kazakhstan, Kyrgyzstan, Lithuania, Latvia, Malta, Poland, Romania, Russian Federation, Slovakia, Slovenia, Ukraine, Republic of Moldova, Tajikistan, Turkmenistan, Uzbekistan.

Other Developing Countries: All countries not included in other groups.

\section{Appendix II. Baseline Projections}

G-Cubed's baseline (no-policy) scenario reflects our judgment about the likely evolution of economic and emissions growth in the absence of concerted policies to control greenhouse gas emissions. Like most studies of climate policies, the results can be sensitive to these baseline projections. Thus, we document here how and why the baseline projections in this study differ from another set of projections many modelers use that is produced by the Energy Information Administration (EIA), an independent analytical arm of the U.S. Department of Energy. The EIA published the International Energy Outlook. The 2009 edition of this report (IEO2009) assesses the outlook for international energy markets through $2030 .{ }^{9}$

The procedure we use to generate our baseline follows the approach in McKibbin, Pearce and Stegman (2009). We specify the expected productivity growth in each sector in the U.S. from 2006 to 2100 . We then specify the gap in the productivity level of each sector in each country relative to the U.S. in 2006 measured in terms of purchasing power parity. We also specify a time varying rate of catch up between each sector in each country and the equivalent U.S. sector. This time varying catch-up rate reflects assumptions about the ability of countries to catch-up and is intended to reflect the evidence in the convergence literature that group of countries catch-up to the technological frontier at different rates and appear to form "convergence clubs".

The final choice variable that we use to reflect historical experience is the rate of autonomous energy efficiency improvement in each production sector in each country as well as in the household consumption bundle.

Given these assumptions and predictions of population growth by country from the United National "medium-variant" projections, we use the model to endogenously generate the rate of economic growth by each country given the endogenous rate of capital accumulation in response to the exogenous drivers of growth and efficiency outlined above. The composition of each economy is generated endogenously as is the energy use and the type of energy use.

\footnotetext{
${ }^{9}$ The IEO2009 is available here: http://www.eia.doe.gov/oiaf/ieo/index.html.
} 
Table A1. Average annual percent change in GDP and emissions 2006-2030.

\begin{tabular}{ccccc}
\hline Region & $\begin{array}{c}\text { GDP growth in } \\
\text { G-Cubed }\end{array}$ & $\begin{array}{c}\text { GDP growth in } \\
\text { IEO2009 }\end{array}$ & $\begin{array}{c}\text { Emissions } \\
\text { growth in } \\
\text { G-Cubed }\end{array}$ & $\begin{array}{c}\text { Emissions } \\
\text { growth in } \\
\text { IEO2009 }\end{array}$ \\
\hline USA & 2.7 & 2.4 & 1.7 & 0.3 \\
Japan & 1.5 & 0.8 & 0.9 & -0.3 \\
Australia & 2.9 & 3.0 & 1.4 & 0.6 \\
Europe & 2.1 & 2.0 & 0.8 & 0.1 \\
ROECD & 2.4 & 2.3 & 0.8 & 0.7 \\
China & 7.4 & 6.8 & 5.8 & 2.8 \\
India & 5.9 & 5.9 & 4.6 & 2.1 \\
EEFSU & 2.5 & 3.9 & 1.2 & 0.7 \\
Brazil & 4.8 & 3.8 & 2.9 & 2.5 \\
LDC & 6.6 & 4.0 & 4.7 & 1.9 \\
OPEC & 4.3 & 4.0 & 3.5 & 1.9 \\
\hline
\end{tabular}

One issue that is immediately obvious in Table A1 is that although the GDP growth rates tend to be similar over the period across the two studies, the rate of improvement in $\mathrm{CO}_{2}$ emissions per unit of GDP are noticeably different. The G-Cubed numbers are consistent with recent historical experience. There is probably a significant amount of policy already embedded in the IEO numbers which may explain some of the difference. The differences may also reflect an endogenously determined structure in G-Cubed that is different to assumptions made in the IEO2009. Either way the results in this paper are different than they would have been had we used the same assumptions as the IEO2009.

\section{References}

Dellink, R, G Briner and C Clapp (2010). Costs, revenues, and effectiveness of the Copenhagen Accord emission pledges for 2020, OECD Environment Working Papers No. 22, OECD Publishing. Available at http://dx.doi.org/10.1787/5km975plmzg6-en.

Jotzo, F (2010). Comparing the Copenhagen emissions targets, CCEP Working Paper 1.10, Centre for Climate Economics \& Policy, Crawford School of Economics and Government, The Australian National University.

McKibbin, WJ and PJ Wilcoxen (1999). The theoretical and empirical structure of the G-Cubed Model. Economic Modelling, 16 (1999), pp. 123-148.

McKibbin, W, A Morris, P Wilcoxen and Y Cai (2009). Consequences of alternative U.S. capand-trade policies: controlling both emissions and costs, The Brookings Institution Available at http://www.brookings.edu/ /media/Files/rc/reports/2009/07_cap_and_trade/0727_cost_containment.pdf.

McKibbin, W, D Pearce and A Stegman (2009). Climate change scenarios and long term projections. Climate Change, 97(1-2), pp 23-47.

United Nations Environment Programme (UNEP) (2010). The Emissions Gap Report: Are the Copenhagen Accord Pledges Sufficient to Limit Global Warming to $2^{\circ} \mathrm{C}$ or $1.5^{\circ} \mathrm{C}$ ? A Preliminary Assessment. 